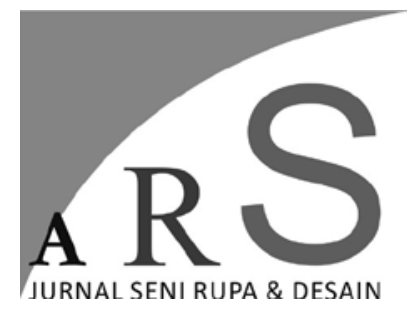

Vol 24 No 1 Januari - Maret 2021 15-20

\section{PERANCANGAN BUKU DECOUPAGE BERDASARKAN DESAIN KOMUNIKASI VISUAL}

\author{
Rizkita Ayu Mutiarani \\ Program Studi Teknik Informatika, STMIK STIKOM Indonesia \\ Tlp.089670940804,E-mail: ayumutiarani@stiki-indonesia.ac.id
}

\begin{abstract}
ABSTRAK
Decoupage merupakan bahasa yang berasal dari Prancis Tengah yaitu "decouper" yang berarti memotong. Decoupage adalah teknik dengan mengambil motif-motif tertentu menjadi sebuah karya yang dapat difungsikan, maupun sebagai media ekspresi visual dari desainer. Saat ini telah masuk era industri 4.0 dengan persaingan yang ketat sehingga generasi muda harus bisa eksis menghadapinya. Salah satu cara dengan decoupage, yaitu dengan memberikan nilai visual yang dipandang dari sisi desain memiliki nilai tertentu sebagai alternatif. Upaya yang dilakukan untuk memberikan makna pada motif-motif decoupage adalah dibuatkannya Buku Decoupage Berdasarkan Desain Komunikasi Visual. Agar masyarakat tidak hanya memotong dan menempelkan motif begitu saja, tetapi juga dapat membuat desain decoupage yang bermakna secara visual. Tujuan dari penelitian ini adalah agar dapat disusun buku tentang decoupage berdasarkan Desain Komunikasi Visual yang terfokus pada prinsip, agar masyarakat memiliki pengetahuan dan inspirasi bernilai estetis. Metode dalam penelitian ini menggunakan penelitian kualitatif, data dikumpulkan melalui observasi lapangan, wawancara, dokumentasi dan kepustakaan, selanjutnya dianlisis dengan metode deskriptif kualitatif.
\end{abstract}

Kata kunci: decoupage, Desain Komunikasi Visual, prinsip desain

\begin{abstract}
Decoupage Book Design Based on Visual Communication Design. Decoupage is a central French language called "decouper" which means to cut. Decoupage is a technique by taking certain motifs into a work that can be functioned, as well as a medium of visual expression from the designer. Currently, it has entered the era of industry 4.0 with stiff competition so that the younger generation should be able to exist against it. One way with decoupage, by providing visual value that is viewed in terms of design to have a certain value as an alternative. So the creativity of the younger generation still has the hope to thrive in the competition. The effort made to give meaning to decoupage motifs in the making of the decoupage book is based on visual communication design. So those people not only cut and paste motifs but can also create visually meaningful decoupage designs. The purpose of this research, the creation of a book on decoupage based on visual communication design focused on principles so that the public has knowledge and inspiration of aesthetic value. The method in this study uses qualitative research, data collected through field observations, interviews, documentation, and literature, further dialysis with qualitative descriptive methods.
\end{abstract}

Keywords: decoupage, Visual Communication Design, design principles 


\section{Pendahuluan}

Decoupage merupakan bahasa yang berasal dari Prancis Tengah yakni "decouper" yang berarti memotong, seni menempelkan potongan kertas atau tisu pada sebuah objek. Decoupage adalah teknik dengan mengambil motif-motif tertentu dan ditempelkan pada sebuah objek menjadi sebuah karya yang dapat berfungsi daya guna, maupun sebagai media ekspresi visual dari sang desainer. Saat ini telah masuk era industri 4.0 yang memiliki persaingan ketat, sehingga generasi muda harus bisa eksis dalam menghadapinya. Salah satu cara dengan decoupage, dengan memberikan nilai visual yang dipandang dari sisi desain sehingga memiliki nilai lebih sebagai akternatif. Sehingga kreativitas generasi muda tetap memiliki harapan untuk berkembang dalam persaingan.

Proses kerajinan decoupage memerlukan bahan seperti paper napkin. Napkin adalah tisu dekoratif yang digunakan untuk menghias benda pakai yang tersedia dalam berbagai motif seperti gambar floral, fauna, geometris, bahkan abstrak, dan lainlain (Santika, 2018). Napkin sendiri memiliki dua jenis yang berbeda karakteristik yaitu Napkin China dan Napkin Eropa.

Selama ini karya decoupage hanya sebatas memotong dan menempelkan tanpa bermakna secara visual. Maka dari itu, penulis akan membuat sebuah buku tentang decoupage berdasarkan Desain Komunikasi Visual. Agar masyarakat tidak hanya memotong dan menempelkan motif-motif begitu saja, tetapi juga membuat desain decoupage menjadi bermakna secara visual.

Tujuan dari penelitian ini adalah menciptakan buku decoupage berdasarkan Desain Komunikasi Visual yang terfokus pada prinsip desain, agar masyarakat memiliki pengetahuan dan inspirasi estetis, dan tidak hanya sekedar memotong dan menempel saja, tetapi juga mampu menata decoupage dari sisi Desain Komunikasi Visual. Sehingga memberikan peluang kepada generasi muda di era industri 4.0 agar mampu menunjukkan kemampuan terbaiknya dalam berkarya. Serta mampu memahami, memaknai setiap motif yang digunakan dan menghasilkan karya yang memiliki nilai lebih yaitu keindahan.

\section{Metode Penelitian}

Pada penelitian ini metode yang digunakan adalah metode kualitatif. Penelitian kualitatif memiliki tahapan pengumpulan data berupa pengamatan, wawancara, dan dokumentasi, dilanjutkan dengan proses analisisi berdasarkan data yang diperoleh. Lalu dikembangkannya pola hubungan tertentu atau menjadi hipotesis (Sugiono, 2015). Pada penelitian ini yang berjudul Perancangan Buku Decoupage Berdasarkan Desain Komunikasi Visual menggunakan metode kualitatif yang akan membahas tentang perancangan yaitu buku untuk mengulik decoupage berdasarkan teori-teori Desain Komunikasi Visual yang terfokus pada prinsip desain, sehingga karya-karya decoupage memiliki keindahan sebagai nilai lebih.

Data kualitatif yang digunakan berupa narasi serta uraian yang terkait dengan permasalahan penelitian. Menurut Patton, pada penelitian kualitatif, data yang digunakan adalah wawancara, pengamatan dan dokumentasi (Emzir, 2011).

Pada penelitian kualitatif, data berupa informasi kata-kata dan bukan angka-angka. Untuk penelitian ini, data yang digunakan adalah buku decoupage berdasarkan Desain Komunikasi Visual.

Penelitian ini menggunakan sumber data primer dan sumber data sekunder. Sumber data primer adalah orang yang aktif dalam kerajinan decoupage yang akan diamati. Sumber primer menghasilkan data berupa hasil dari wawancara berkaitan dengan dengan buku decoupage. Sumber data sekunder yaitu sumber data yang dihasilkan dari dokumen, seperti laporan, tesis, buku, jurnal, teks yang sesuai dengan permasalahan yang diangkat.

\section{Teori}

Teori yang digunakan untuk mengupas permasalahan yang diangkat adalah teori Desain Komunikasi Visual dan estetika untuk menyusun buku decoupage. 
Desain Komunikasi Visual memiliki peran atau informasi kepada pembaca dengan berbagai kekuatan visual, seperti ilustrasi, tipografi, warna, dan sebagaiamnya dengan bantuan teknologi (Supriyono, 2010).

Desain Komunikasi Visual memiliki tiga fungsi dasar (Cenadi, 1999) yaitu: (1) Desain Komunikasi Visual sebagai Sarana Identifikasi, (2) Desain Komunikasi Visual sebagai Sarana Informasi dan Instruksi, dan (3) Desain Komunikasi Visual sebagai Sarana Presentasi dan Promosi.

Teori Desain Komunikasi Visual menggunakan elemen-elemen visual dalam penyusunan desain, diantaranya: (1) Ilustrasi merupakan gambar atau foto yang bertujuan menjelaskan teks dan untuk menciptakan daya tarik; (2) Warna merupakan salah satu elemen visual yang sangat kuat dan provokatif, karena pemakaian warna yang tidak tepat akan dapat merusak citra; (3) Tipografi merupakan pemilihan jenis dan karakter huruf, agar pembaca secara cepat, mudah dan menyenangkan dalam penyampaian informasi.

Untuk menghasilkan suatu komposisi desain yang baik dan harmonis diperlukan prinsipprinsip desain yang meliputi: keseimbangan, irama, penekanan, dan kesatuan.

\section{Hasil dan Pembahasan}

Konsep dasar yang digunakan dalam perancangan buku decoupage berdasarkan Desain Komunikasi Visual adalah "Vitange" yang menyesuaikan dengan tema yang diambil. Menurut Kamus Oxford, kata vintage berarti old and of very high quality, dengan makna klasik dan berkualitas tinggi. Desain vintage mengacu pada gaya klasik dan antik yang mengadopsi sekitar tahun 1920-an sampai 1950-an yaitu pada era pertengahan modern (mid-century) atau biasa disebut era nostalgia (Okvitasari, 2019). Memilih konsep vintage karena penulis memiliki harapan untuk menonjolkan kerajinan decoupage yang terkesan klasik, namun bisa diterapkan di era industri 4.0 oleh kaum milenial.

Strategi media yang akan digunakan untuk pengaplikasian decoupage adalah berupa buku. Buku decoupage menyasar target audiens yaitu kaum milenial umur sekitar 20-35 tahun dengan tingkat ekonomi menengah ke bawah. Sedangkan strategi kreatif yang digunakan untuk perancangan buku adalah pesan yang disampaikan kepada target audiens berupa penerapan prinsip desain pada motif decoupage berdasarkan Desain Komunikasi Visual. Agar target audiens mampu memberikan nilai lebih berupa keindahan pada motif-motif decoupage. Bentuk pesan dimunculkan menggunakan ilustrasi berupa foto, serta tipografi dan teks menggunakan konsep vintage untuk mengidentifikasi decoupage itu sendiri. Aspek-aspek yang dipertimbangkan adalah ilustrasi, warna, tipografi, dan teks.

Ilustrasi. Dalam perancangan buku decoupage, ilustrasi dominan yang ditampilkan adalah ilustrasi dengan motif-motif decoupage yang dihasilkan dari teknik fotografi. Ilustrasi motif decoupage yang dominan digunakan adalah bermotif flora, fauna serta kombinasinya (Gambar 1). Warna yang digunakan pada buku decoupage selain warna pada motif-motif napkin decoupage adalah warna yang mencerminkan penerapan dari konsep desain vintage yaitu coklat (Gambar 2).

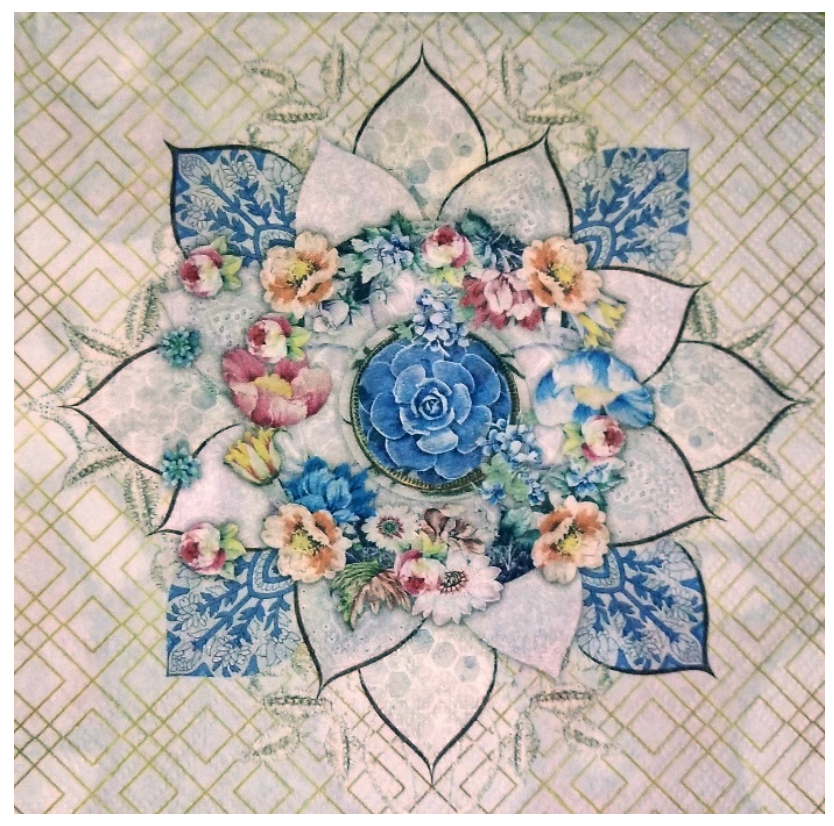

Gambar 1. Napkin Decoupage

(Sumber: Dokumentasi Rizkita, 2020) 


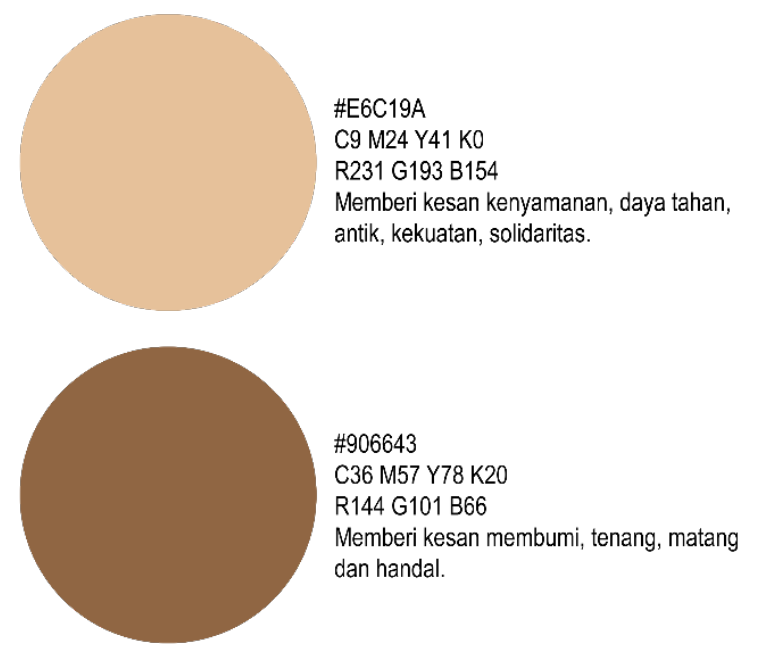

Gambar 2. Penerapan warna pada buku decoupage (Sumber: Dokumentasi Rizkita, 2020)

\section{Decoupage}

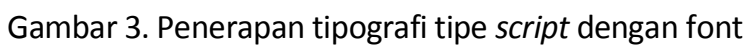
Mustard Personal Use pada buku decoupage

(Sumber: Dokumentasi Rizkita, 2020)

\section{Decoupage}

Gambar 4. Penerapan tipografi tipe sans serif dengan font Calibri pada buku decoupage

(Sumber: Dokumentasi Rizkita, 2020)

Tipografi. Buku decoupage menggunakan tipografi tipe script yang menyerupai tulisan tangan dengan font Mustard Personal Use (Gambar 3). Tipe tipografi ini dipilih karena akan memperlihatkan keakraban atau kenyamanan. Digunakan juga tipografi tipe sans serif atau huruf tanpa kait/kaki pada teks konten buku decoupage dengan font Calibri (Gambar 4). Tipe tipografi ini akan memberikan kesan sederhana, tetapi tetap enak dilihat.

Teks yang akan ditampilkan adalah isi dari konten buku decoupage bertujuan untuk menginformasikan kepada target audiens makna dari motif decoupage dilihat dari sisi Desain Komunikasi Visual (Gambar 5).
Keseimbangan merupakan adanya kesamaan bagaikan cermin, dapat pula diperoleh dengan bentuk yang berbeda saat dicerminkan.

Gambar 5. Penerapan teks pada buku decoupage (Sumber: Dokumentasi Rizkita, 2020)

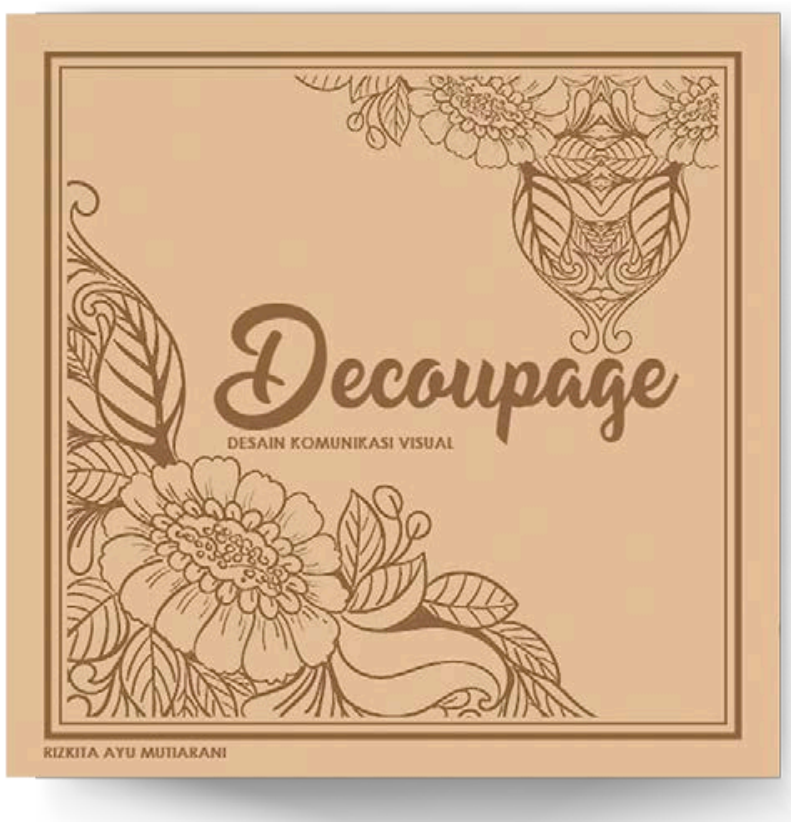

Gambar 6. Mock up Sampul Depan Buku Decoupage Berdasarkan Desain Komunikasi Visual (Sumber: Dokumentasi Rizkita, 2020)

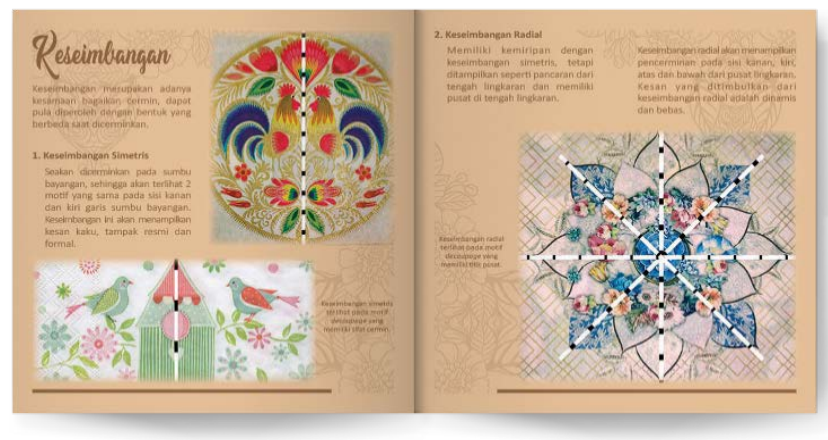

Gambar 7. Mock up Buku Decoupage Berdasarkan Desain Komunikasi Visual

(Sumber: Dokumentasi Rizkita, 2020)

\section{Visualisasi Desain}

Merupakan bagian yang paling bebas untuk penulis berekspresi. Jangan berpanjang lebar, tetapi berargumenlah dengan logis. Dalam membahasnya ulaslah penelitian memenuhi tujuan penelitian (Gambar 7-9). 


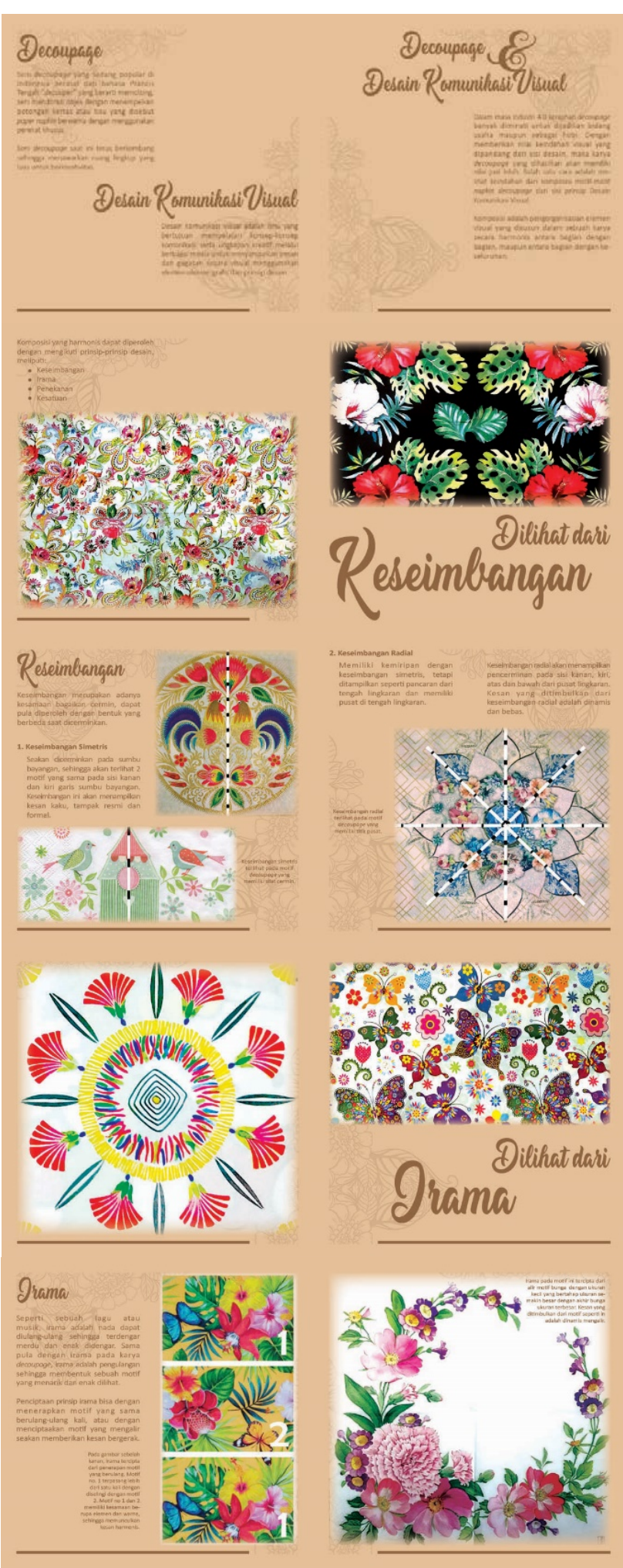

Gambar 8. Mock up dari halaman Buku Decoupage Berdasarkan Desain Komunikasi Visual (Sumber: Dokumentasi Rizkita, 2020)

Hubungkan temuan dengan pengamatan atau hasil penelitian sebelumnya dengan jalan menunjukkan persamaan dan membahas perbedaannya

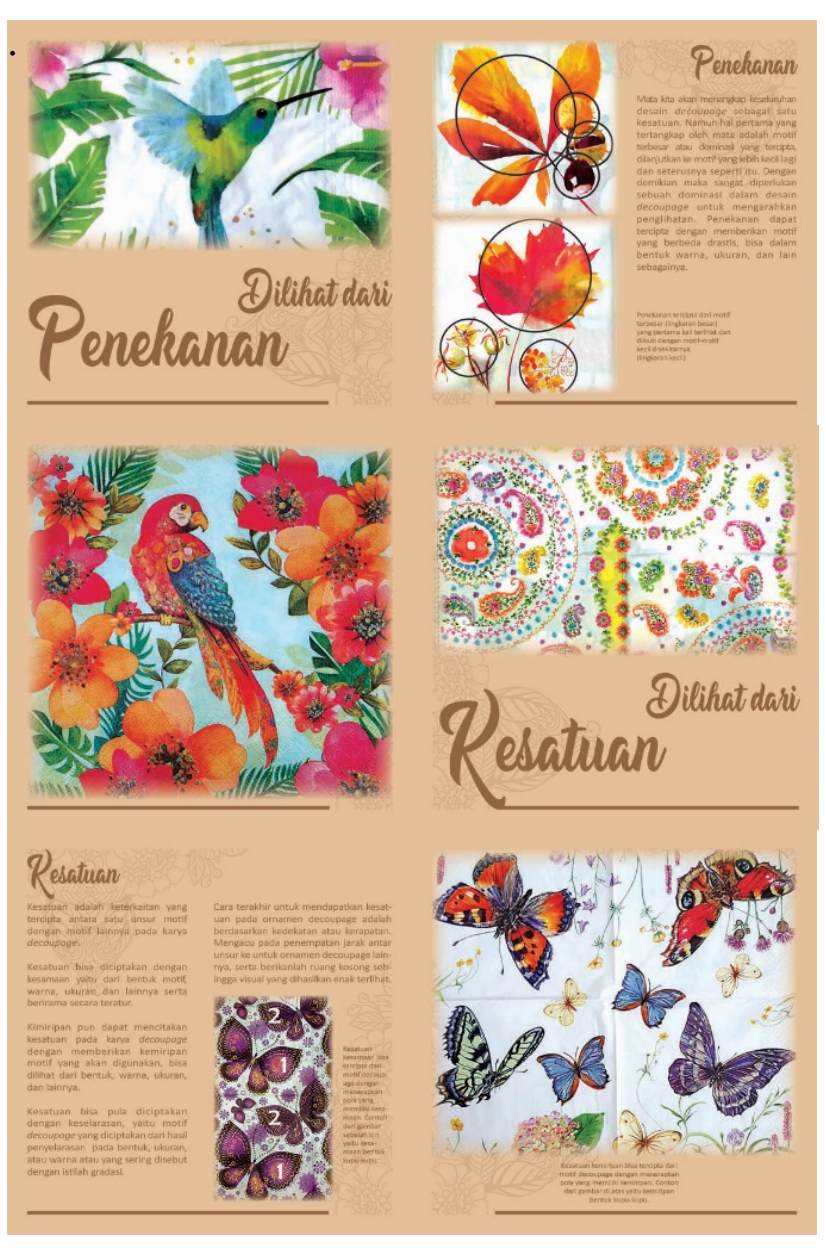

Gambar 9. Mock up dari halaman Buku Decoupage Berdasarkan Desain Komunikasi Visual (lanjutan)

(Sumber: Dokumentasi Rizkita, 2020)

\section{Kesimpulan}

Dalam dunia industri saat ini diperlukan suatu kreativitas dalam usaha untuk bersaing. Salah satunya adalah memaknai motif-motif napkin decoupage dan akan digunakan untuk menghiasi media yang akan dijadikan bidang usaha maupun sebagai hobi. Makna-makna tersebut dapat dilihat dari prinsip-prinsip desain yang terkandung di dalamnya, sehingga dapat menambah nilai lebih berupa keindahan. Dalam mendesain buku decoupage. Dalam mendesain buku decoupage berdasarkan Desain Komunikasi Visual menggunakan konsep dasar "vintage". Elemen desain yang digunakan pada perancangan buku adalah ilustrasi, warna, tipografi dan teks.

\section{Kepustakaan}

Cenadi, C. S. (1999). Corporate Identity: Sejarah 
Dan Aplikasinya. Nirmana, 1(2).

Emzir, A. D. (2011). Metodologi Penelitian Kualitatif. Jakarta: Rajawali Pers.

Okvitasari, H. (2019). Desain Interior Pusat Fashion dengan Konsep Vintage di Surakarta. Santika, R. T. (2018). Perbedaan hasil jadi teknik aplikasi decoupage menggunakan kain satin sutra, satin acetat, dan satin polyester pada busana pesta anak. Jurnal Tata Busana, 7(2).
Sugiono. (2015). Metode Penelitan Kuantitatif. Bandung: Alfabeta.

Supriyono, R. (2010). Desain Komunikasi Visual Teori dan Aplikasi. Yogyakarta: Andi.

Zakiyah, N. L. (2020). Buku ilustrasi pola asuh yang tepat untuk menumbuhkan emosi positif anak. Ars: Jurnal Seni Rupa Dan Desain, 23(3), 136-145. 